ARTIGOS

Submetido 14.06.2013. Aprovado 04.09.2014

Avaliado pelo processo de double blind review. Editor Científico: Fernanda Finotti Perobelli

DOI:http://dx.doi.org/10.1590/So034-759020150309

\title{
EFEITOS DA VINCULAÇÃO DE CONSELHEIROS AO ACORDO DE ACIONISTAS NO VALOR DA FIRMA
}

\author{
Effects of the involvement of counselors to the agreement of shareholders to the \\ values of the firm
}
Efectos de la vinculación de consejeros al acuerdo de accionistas en el valor de la firma

\section{RESUMO}

Este artigo tem como objetivo analisar o efeito das cláusulas que vinculam o voto dos conselheiros ao acordo de acionistas no valor da firma. A partir de uma base de dados de 181 empresas listadas nos segmentos especiais da BM\&FBovespa entre os anos de 2008 e 2012, estudamos o efeito da inclusão de cláusulas genéricas e específicas de vínculo de voto no valor das empresas. Verificamos um efeito negativo do acordo de acionistas no valor da firma, que se acentua na presença de cláusulas genéricas e se ameniza na presença de cláusulas específicas de vínculo de voto ao acordo de acionistas. Esses resultados são consistentes mesmo controlando pela endogeneidade da decisão pelo acordo de acionistas. Assim, os resultados apontam para um "efeito entrincheiramento" dos acionistas de controle no uso dos acordos de acionistas como mecanismo de compartilhamento de controle e voto. Este artigo contribui para a literatura em governança e finanças corporativas ao revelar práticas que enfraquecem a atuação de um dos principais pilares de governança, o conselho de administração.

PALAVRAS-CHAVE | Acordos de acionistas, cláusula vinculante, valor da firma, Novo Mercado, governança corporativa.

\section{ABSTRACT}

This study analyzes the effect of shareholders' agreement binding provisions on firm value. Using a database of 181 publicly listed firms from the special segments of the BM\&FBovespa, between 2008 and 2012, we analyze the effect of the inclusion of generic and specific clauses into the shareholder agreement bind director's vote to the agreement on firm value. The results indicate a negative effect of the shareholders' agreement on firm value. This effect is higher in the presence of generic clauses and lower in the presence of specific clauses, even after controlling for the endogeneity of the shareholders' decision to adopt shareholder agreements. The results allow us to conclude that controlling shareholders use the shareholder agreements as a mechanism to enhance control at the expense of firm value (entrenchment effect). This article contributes to the literature on governance and corporate finance to reveal practices that weaken the role of one of the main pillars of governance, the board of directors.

\section{MARINA GELMAN}

marinaogelman@gmail.com Mestre em Direito pela Fundação Getulio Vargas, Escola de Direito de São Paulo - São Paulo - SP, Brasil

\section{LUIZ RICARDO KABBACH DE CASTRO} luiz.kabbach@sc.usp.br Professor da Universidade de São Paulo, Escola de Engenharia de São Carlos - São Carlos - SP, Brasil

\section{VALENTIN SEIDLER}

valentin.seidler@univie.ac.at

Professor da Universität Wien, Institut für Internationale Entwicklung - Viena, Áustria
KEYWORDS / Shareholder agreements, binding provisions, firm value, Novo Mercado, corporate governance.

\section{RESUMEN}

Ese artículo tiene como objetivo analizar el efecto de las cláusulas que vinculan el voto de los consejeros al acuerdo de accionistas en el valor de la firma. A partir de una base de datos de 181 empresas listadas en los segmentos especiales de la BM\&FBovespa entre los años de 2008 y 2012, estudiamos el efecto de la inclusión de cláusulas genéricas y específicas de vínculo de voto en el valor de las empresas. Verificamos un efecto negativo del acuerdo de accionistas en el valor de la firma, que se acentúa en la presencia de cláusulas genéricas y se ameniza en la presencia de cláusulas específicas de vínculo de voto al acuerdo de accionistas. Eses resultados son consistentes aún controlando por la endogeneidad de la decisión por el acuerdo de accionistas. Así, los resultados apuntan a un "efecto atrincheramiento" de los accionistas de control en el uso de los acuerdos de accionistas como mecanismo de compartimiento de control y voto. Ese artículo contribuye con la literatura en gobernanza y finanzas corporativas al revelar prácticas que enfranquecen la actuación de uno de los principales pilares de gobernanza, el consejo de administración.

PALABRAS-CLAVE / Acuerdos de accionistas, cláusula vinculante, valor de la firma, Nuevo Mercado, gobernanza corporativa. 


\section{INTRODUÇÃO}

A partir das crises financeiras de 1998 ocorridas na Rússia, Ásia e Brasil, o mundo viveu a experiência de que os atos das grandes corporações são capazes de afetar economias inteiras, como de fato ocorreu, pois todo o sistema financeiro mundial sofreu abalo em sua estabilidade por questões de fragilidade nas práticas de governança corporativa (Claessens, 2006).

Berle e Means (1932) e Jensen e Meckling (1976) colocam no centro dessa discussão a separação entre propriedade e controle das empresas, assumindo que o problema central da governança corporativa está na relação entre a estrutura de propriedade e os conflitos de interesse na alta gestão da empresa. Estudos empíricos em diferentes países tentam explicitar quais são e como se resolvem esses conflitos. Nos Estados Unidos e Reino Unido, o problema de governança está relacionado ao conflito entre acionistas minoritários e administradores, onde a estrutura de propriedade é dispersa e os investidores institucionais são mais recorrentes (Coffee, 2001). Por outro lado, o problema fundamental da governança corporativa em países emergentes, incluindo o Brasil, e na maior parte do mundo é diferente do observado nos países anglo-saxões (Claessens, Djankov, \& Lang, 2000; Faccio \& Lang, 2002; La Porta, López-de-Silanes, \& Shleifer, 1999). Nesses países, a estrutura de propriedade de companhias abertas é mais concentrada e, em geral, elas possuem um acionista majoritário, muitas vezes um indivíduo ou família, que detém a maioria dos direitos de voto da empresa. Por exemplo, no Brasil, as empresas listadas na BM\&FBovespa possuem, em sua maioria, acionistas majoritários detentores da maioria do capital votante (Aguilera, Kabbach, Lee, \& You, 2012; Aldrighi \& Mazzer-Neto, 2007; Aldrighi \& Postali, 2010; Leal \& Carvalhal-da-Silva, 2007), onde o principal problema de governança diz respeito ao conflito de interesses entre acionistas controladores e minoritários.

Um dos mecanismos utilizados para aumentar o poder de controle dos acionistas é o acordo de acionistas (AA) (La Porta et al, 1999). O AA constitui um contrato celebrado entre acionistas de determinada empresa visando à conciliação de interesses individuais e ao estabelecimento de normas de atuação na sociedade (Eizirik, 2011). Em geral, esses acordos são uma tentativa dos acionistas para efetivamente controlar as decisões e a gestão da empresa. Embora, é claro, os acionistas exerçam sua participação na administração por meio do voto nas assembleias gerais, os AAs servem para compor interesses de acionistas que, por si só, não poderiam influir nos destinos da companhia (Wright, 1971). Por exemplo, por meio de um acordo de voto, os acionistas convenentes obrigam-se a votarem em bloco, seja a favor ou contra uma determinada deliberação da assembleia, ou para estabelecer que seus membros votarão em conjunto para eleger o conselho de administração. Ou, ainda, os acionistas podem celebrar um acordo de controle que congrega os acionistas, os quais, em conjunto, passam a deter a quantidade de ações votantes que lhes assegure o poder de eleger a maioria dos administradores.

Esses acordos têm um papel importante na governança de empresas em diversos países, incluindo os Estados Unidos e países europeus (Baglioni, 2010; Chemla, Habib, \& Ljungvist, 2007). Na Europa, Capresse, Clerc e Becht (2007) evidenciam que o AA é utilizado em $14 \%$ das empresas das 464 companhias analisadas como mecanismo para alcançar o poder de controle. Os países onde os AAs são mais frequentes são: Bélgica (31\% das empresas), Itália (23\%), França (18\%) e Espanha (13\%). Gomes e Novaes (2006) reportam que, de uma amostra aleatória de 115 companhias abertas americanas, 46\% apresentam AAs referentes a poder de veto, acordos de voto e controle do conseIho de administração. No Brasil, Gorga e Gelman (2012) e CarvaIhal-da-Silva (2012) reportam o crescente uso desse mecanismo em empresas nacionais.

Essas diferenças nas estruturas de propriedade, e seus mecanismos de controle, observadas em diversos países, têm duas implicações importantes para a governança corporativa. Por um lado, em empresas com capital pulverizado, por causa de um problema de ação coletiva, os minoritários não têm incentivos para coletar informações e supervisionar os administradores. Uma maneira de reduzir a assimetria de informação entre insiders e outsiders e melhorar a governança corporativa é assegurar que uma empresa tenha, pelo menos, um acionista majoritário. Esse acionista, com uma fração substancial da propriedade e controle, teria incentivo, para suportar os custos econômicos do monitoramento, e poder, para disciplinar os administradores. Por outro lado, uma alta concentração de propriedade (e controle) nas mãos de um único acionista (ou um pequeno grupo de acionistas) leva a outro problema: o conflito de interesses entre acionistas minoritários e majoritários é mais pronunciado (Morck, Wolfenzon, \& Yeung, 2005; Young, Peng, Ahlstrom, Bruton, \& Jiang, 2008).

Nesse contexto, o conselho de administração, por sua função de monitoramento e fiscalização da gestão das companhias, é considerado um mecanismo central de boa governança corporativa capaz de mitigar as fragilidades do processo de administração de uma empresa (Enriques \& Volpin, 2007). Para cumprir esse papel, contudo, é relevante que o conselho possa agir de maneira profissional, técnica, livre de influências, portanto independente. Caso as empresas tenham uma estrutura de propriedade dispersa ou sejam controladas por um acionista majoritário, o perigo é que o conselho de administração, em 
vez de representar os interesses da empresa (e, portanto, também dos acionistas minoritários), tenha vínculos estreitos com a administração (ou com o acionista majoritário) com a qual interage com regularidade, perdendo sua independência, quando sua função é monitorá-la.

No Brasil, embora a legislação vigente crie para o membro do conselho de administração o dever de independência, permite, ao mesmo tempo, paradoxalmente, que acionistas se componham contratualmente por meio de AAs no sentido de coordenar não apenas seu voto como também o voto dos conselheiros por eles eleitos no âmbito desses acordos.

Assim, o objetivo deste artigo é avaliar se a existência de cláusulas vinculantes do voto dos conselheiros ao AA condiciona o desempenho das empresas listadas nos segmentos especiais da BM\&FBovespa, com base no seu valor de mercado. Para isso, analisamos o efeito dos AAs no valor das empresas. Nesse aspecto, este estudo assemelha-se ao de Carvalhal-da-Silva (2012). Enquanto o autor desenvolve um índice para medir o grau de proteção ao investidor proporcionado pelos acordos e seu impacto no valor da firma, nosso trabalho parte da relação entre $A A$ e valor da firma e estende a análise para capturar o efeito moderador da presença de cláusulas de vínculo do voto do conselho (Baron \& Kenny, 1986).

Ao analisar o efeito da presença de cláusulas vinculantes genéricas e específicas dos AAs no valor da firma, pretendemos avaliar empírica e economicamente o impacto da revisão da legislação brasileira, que, a partir de 2001, permitiu o uso desses mecanismos de governança e, dessa forma, contribuir para o debate jurídico sobre a eficácia desse ordenamento para o mercado de capitais.

O trabalho está organizado da seguinte maneira: a próxima seção traz uma revisão da literatura sobre AAs e apresenta as hipóteses de estudo. Na sequência, detalhamos a metodologia utilizada, bem como descrevemos a amostra e as variáveis utilizadas, cujos resultados são apresentados na seção seguinte. Finalmente, discutimos os resultados e concluímos apresentando algumas implicações, limitações e sugestões para estudos futuros.

\section{REVISÃO DA LITERATURA E HIPÓTESES}

\section{O contexto jurídico brasileiro dos acordos de acionistas}

No Brasil, desde 1976, com o advento do marco regulatório representado pela Lei das Sociedades Anônimas (Lei $n$. $6.404 / 1976$ - LSA), o formato de gestão de uma companhia de capital aberto divide-se em três instâncias políticas: a assembleia de acionistas, o conselho de administração e a diretoria. Mais ainda, nas companhias de capital aberto, essa tripartição de poderes é compulsória, pelo que, no Brasil, não existe companhia de capital aberto sem conselho de administração.

A intenção dos legisladores quando da criação compulsória do conselho de administração nas companhias de capital aberto era de garantir a representatividade da assembleia de acionistas nesse órgão, que é a maior instância administrativa de uma companhia (Exposição de Motivos n. 196, de 24 de junho de 1976, Ministério da Fazenda). Por outro lado, e ainda no mesmo sentido de promover a proteção do investidor minoritário, a LSA atribuiu, ao conselho de administração, além de outros deveres que não são objeto deste estudo, o dever de independência. Assim, de acordo com a lei, os membros do conselho de administração devem agir sempre no interesse da companhia, e não em defesa de qualquer outra parte interessada, nem mesmo seus eleitores.

Ocorre que a mesma LSA que cria a obrigatoriedade de um órgão de gestão independente confere aos acionistas de uma companhia a oportunidade de alinharem seu voto e, mais ainda, de determinarem o voto dos administradores por eles eleitos, por meio de AAs.

Desde sua origem, em 1976, a LSA já dispunha que os AAs que versassem, entre outros temas, sobre exercício do direito de voto deveriam ser observados quando arquivados na sede das sociedades. Contudo, a LSA não tratava explicitamente da possibilidade de os votos dos membros do conselho de administração serem vinculados à decisão prévia dos acionistas partes dos AAs. Em 2001, a atuação do conselho de administração foi profundamente impactada pela reforma da LSA, por meio da introdução de dois parágrafos específicos ( $\S \S 8^{\circ} \underline{0}$ e 9ํำ no artigo 118), que, para dar mais força executiva e eficácia aos AAs, tornaram obrigatória a observação dos AAs pelos administradores das companhias. Em particular, esses novos parágrafos determinam que: (a) o membro do conselho de administração, eleito por partes de um AA, que eventualmente discordar de uma decisão tomada previamente e, assim, votar de maneira divergente da indicada pelo grupo signatário do acordo, não terá seu voto computado pelo presidente do conselho (§ $\left.8^{\circ}\right)$, e (b) assegurar à parte prejudicada - pela falta do voto do acionista ou conselheiro que se ausentar ou se abster - o direito de votar por aquele que faltou ou se absteve ( $\left(9^{9}\right.$ ).

Assim, não apenas o voto divergente do membro do conselho não pode ser computado, como também outro membro, eleito pelo mesmo grupo de acionistas parte do AA, terá o direito de votar em seu lugar. Com esses dispositivos legais, o sistema normativo consolidou a força vinculante dos AAs e trouxe à 
tona o debate entre compatibilidade do dever de independência e vinculação dos administradores a AAs.

Do ponto de vista jurídico, existem duas interpretações acerca do efeito desse potencial paradoxo entre dever de independência e vinculação de voto. Por um lado, existem autores os quais argumentam que o dever de independência se compatibiliza com a vinculação de voto dos administradores porque 0 acordo de controle atende ao interesse social, pelo que a vinculação dos administradores ao exercício do voto em atendimento ao interesse social está plenamente de acordo com seu dever de independência (Aragão, 2002; Carvalhosa, 2009, 2011; Eizirik, 2003; Pedreira, 2002).

De outro lado, estão os que entendem que a razão para compatibilizar os dois dispositivos encontra fundamento em uma interpretação sistemática da lei e que, por considerarem inabalável o dever de independência, entendem que os administradores têm seu voto vinculado ao $A A$, mas mantêm sua independência para se abster de tal obrigação sempre que entenderem que seu cumprimento contraria o interesse social (Adamek, 2009; Cerezetti, 2010; Salomão, 2006; Wald, 2001, 2002a, 2002b).

Esse debate reparte-se, ao final, em três grupos doutrinários: (i) os que entendem que não há incompatibilidade entre os respectivos dispositivos legais porque, em suma, o interesse do grupo de controle é o próprio interesse social e, assim, atendê-lo nada mais é do que dever dos administradores; (ii) os que entendem que não há incompatibilidade porque, não tendo sido revogado o dever de independência, o administrador, mesmo quando vinculado a acordo de acionistas, pode resistir ao dever de dar cumprimento ao acordo em nome do referido dever de independência; e (iii) os que entendem que os dois dispositivos são incompativeis e que a introdução dos $\S \S 8^{\circ}$ e $9^{0}$ no artigo 118 da LSA criou uma regra que compromete o dever de independência (Bocater \& Camargo, 2001; Franco, 2001; Toledo, 2002).

Mas qual seria o efeito econômico desse debate jurídico?

\section{0 efeito econômico dos acordos de acionistas e cláusulas vinculantes}

Desde uma perspectiva econômica da governança corporativa, Hart (1995) argumenta que um problema de governança em companhias abertas emerge quando existe um problema de agência (um conflito de interesses entre o "principal" - os acionistas - e o "agente" - os administradores) que não pode ser resolvido por meio de um contrato. Berle e Means (1932) e Jensen e Meckling (1976) discutem que, para resolver esses conflitos de interesses, as empresas incorrem em custos, e definem os custos de agência como a soma dos custos de monitoramento das atividades do agente pelo principal, os custos de elaboração do contrato entre o agente e o principal e perda residual decorrente das decisões do agente contrárias aos interesses do principal.

Assim, os mecanismos de governança corporativa foram desenvolvidos para minimizar esses custos de agência. Em particular, tendo em conta que os acionistas minoritários têm pouco incentivo para monitorar a administração, autores têm sugerido que, para melhorar a governança corporativa de uma empresa, bastaria a presença de um acionista majoritário (Hart, 1995; Shleifer \& Vishny, 1986). Na prática, vários estudos mostram uma significativa concentração de propriedade e a existência desses acionistas majoritários na Alemanha (Franks \& Mayer, 2001), no Japão (Berglöf \& Perotti, 1994), na Europa (Faccio \& Lang, 2002), em países asiáticos (Claessens et al, 2000), em economias em desenvolvimento (La Porta et al, 1999), e no Brasil (Aguilera et al, 2012; Aldrighi \& Mazzer-Neto, 2007; Aldrighi \& Postali, 2010; Leal \& Carvalhal-da-Silva, 2007).

No entanto, um acionista majoritário pode não ter os incentivos necessários para monitorar a administração, uma vez que o custo de monitoramento é suportado somente por ele, enquanto os benefícios são aproveitados por todos os acionistas (Grossman \& Hart, 1980). Ou, ainda, um acionista majoritário pode usar seu poder para melhorar a sua posição às custas de outros acionistas, dando origem a outro problema de agência, relacionado com o conflito de interesses entre os acionistas minoritários e majoritários (Burkart, Gromb, \& Panunzi, 1997).

Assim, por meio de um acordo de acionistas, uma nova estrutura de governança surge, na qual múltiplos acionistas podem desfrutar os benefícios privados e os acionistas minoritários não necessitam contar com a boa-fé de um único acionista controlador que cuide de seus interesses. Desde uma perspectiva econômica de governança corporativa, os AAs podem apresentar duas consequências fundamentais.

Por um lado, o controle compartilhado pode aumentar o valor das empresas, por duas razões. Primeiro, ao aumentar sua participação acionária na empresa, os acionistas signatários passam a ter o poder e os incentivos econômicos para aumentar o valor da empresa e para monitorar o comportamento gerencial, reduzindo custos de agência, o chamado "efeito dos incentivos” (Claessens, Djankov, Fan, \& Lang, 2002; Gomes \& Novaes, 2006). Segundo, problemas de negociação coletiva entre os acionistas convenentes reduzem a possibilidade de que o bloco de controle tome decisões que beneficiem o grupo em detrimento dos minoritários (Gomes \& Novaes, 2006). Assim, propõe-se:

H1a. Os acordos de acionistas têm um efeito positivo no valor das empresas (efeito incentivos).

Por outro lado, esse aumento do poder de controle pode levar a uma série de outros problemas de agência, sobretudo aque- 
les relacionados com a divergência de interesses entre majoritários e minoritários, em que os acionistas signatários do AAs podem extrair benefícios privados de controle em detrimento dos acionistas minoritários, o "efeito entrincheiramento" (Morck et al, 2005).

Em particular, em economias onde a proteção ao investidor é menor, como no caso do Brasil, o prêmio de controle é maior (Djankov, La Porta, López-de-Silanes, \& Shleifer, 2008), sinalizando que, de alguma forma, o mercado precifica algum benefício privado de controle que não poderia ser aproveitado por todos os acionistas. Assim, a existência dos conflitos de agência e dos altos benefícios privados de controle nas companhias abertas brasileiras nos impede de assumir que os AAs estarão sempre de acordo com o interesse social da companhia (e, por consequência, dos minoritários).

Ainda que existam instituições e leis que protejam os minoritários, como em países desenvolvidos, a possibilidade de expropriação do acionista majoritário por vias legais é não somente possível mas real Johnson, La Porta, López-de-Silanes, \& Shleifer, 2000). Johnson et al. (2000) citam que a "expropriação legal" pode ocorrer sob diversas formas, incluindo: preços de transferência favorecendo o acionista (ou bloco) controlador, transferência de ativos entre empresas coligadas, aquisições a preços divergentes dos preços de mercado e garantias de empréstimos usando os ativos da companhia, sendo a mais comum a diluição das ações dos minoritários.

Esses autores identificam ainda que, em países nos quais a origem legal é baseada no direito civilista romano, a expropriação dos acionistas minoritários pelo controlador (ou bloco de controle) é, muitas vezes, vista como consistente com os deveres fiduciários dos administradores, sobretudo quando envolve empresas de um mesmo grupo econômico. Assim, uma atividade de expropriação é analisada à luz de sua conformidade com os estatutos da companhia, e não com base na equidade entre os acionistas controladores e minoritários. Nesse contexto, os AAs podem ser interpretados como mecanismos dos acionistas controladores para aumentar os benefícios privados de controle. Ante o exposto, propõe-se:

H1b. Os acordos de acionistas têm um efeito negativo no valor da empresa (efeito entrincheiramento).

A análise anterior pressupõe que os AAs, por si só, poderiam ter algum efeito, positivo ou negativo, no valor das empresas. Entretanto, ainda que necessária, essa análise não seria suficiente para identificar o efeito no valor das empresas, uma vez que pode haver cláusulas que facilitem ou reduzam os benefícios privados de controle dos controladores.

Por exemplo, em ambientes institucionais de baixa proteção aos minoritários, os acionistas podem lançar mão de cláu- sulas que vinculem, ex-ante, os votos e decisões dos acionistas signatários e, mais ainda, dos administradores e conselheiros. Enrique e Volpin (2007) demonstram que o vínculo de voto dos acionistas e administradores em empresas europeias servem como instrumentos para aumentar o poder de controle sem relação direta com benefícios aos minoritários. Mais ainda, como resultado dessas práticas, na Itália, em 1998, uma reforma regulatória (Dragui Law) passou a restringir o uso de cláusulas de vínculo de votos.

No Brasil, a partir da revisão da LSA, em 2001, a legislação permite aos acionistas signatários de um AA vincular ao acordo, de maneira indiscriminada e universal (genérica), o voto dos acionistas e administradores por eles indicados nas decisões colegiadas da empresa. Tal vinculação esvazia o poder-dever de independência dos conselheiros para tomarem as decisões segundo seu dever fiduciário para com o interesse social da companhia, impedindo, portanto, aqueles conselheiros vinculados ao AA de monitorar a administração, mas, agora, exercendo-a em nome dos acionistas signatários.

Dessa forma, o poder de controle e, sobretudo, o poder sobre as decisões dos conselheiros (voto), que permite determinar as estratégias das empresas, tais como políticas de dividendos, investimentos, alocação de capital, entre outras, que finalmente afetam o valor da companhia, podem tomar decisões em detrimento da maximização do valor da companhia, para proporcionar os benefícios privados dos acionistas signatários, o que nos leva à seguinte hipótese:

H2. Com a presença, no acordo de acionistas, de cláusulas que vinculam os votos dos conselheiros de maneira indiscriminada (vínculo genérico), o efeito positivo (negativo) do acordo de acionistas no valor da firma será menos positivo (mais negativo) (efeito entrincheiramento).

Finalmente, a própria lógica do AA pressupõe a existência de cláusulas que o regulem, e, nesse sentido, cabe analisar, em particular, a que vincula o voto dos acionistas signatários, e os conselheiros por eles nomeados, as matérias específicas, relevantes e extraordinárias, expressamente previstas no acordo.

Considerando que o AA tem por objetivo compor interesses individuais e estabelecer normas de atuação na sociedade, a vinculação específica de voto, ex-ante, sobre matérias relevantes visa eliminar incertezas, ex-post, oriundas da renegociação de temas que, em princípio, definiram o objeto do acordo. Nesse sentido, a Corte nova-iorquina, no caso Manson versus Curtis, postulou que "os acionistas têm o direito de combinar seus interesses e poderes de voto para assegurar o controle e para garantir a adoção e adesão a estes interesses de políticas e decisões específicas relacionadas ao negócio" (Wright, 1971, p. 502). 
Chemla et al. (2007) argumentam que, num contexto de problemas de agência e de risco moral dinâmico onde os contratantes - acionistas - possam renegociar todas as situações futuras, o vínculo de voto em matérias específicas permite uma alocação eficiente dos investimentos dos acionistas signatários no momento de assinatura do acordo (ex-ante). Isso se dá pela simples restrição de um processo de renegociação custoso à empresa e aos acionistas. Assim, na ausência dessas cláusulas, o valor dos investimentos na data do acordo estaria distorcido pela possibilidade irrestrita de renegociações que visem ao benefício particular de partes isoladas do acordo de acionistas no futuro, o que nos leva à seguinte hipótese:

H3. Com a presença, no acordo de acionistas, de cláusulas que vinculam os votos dos conselheiros de maneira específica a matérias extraordinárias previstas no próprio acordo (vinculo especifico), o efeito positivo (negativo) do acordo de acionistas no valor da firma será mais positivo (menos negativo) (efeito incentivo).

Em resumo, propomos que os acordos de acionistas podem ter como objetivo trazer para o grupo de controle um investidor que, sendo parte no acordo, possa monitorar os majoritários em benefício de toda a comunidade de acionistas e, portanto, o AA terá um efeito positivo no valor da empesa ( $\left.\mathrm{H}_{1} a\right)$. Por outro lado, o AA pode também servir como facilitador para que as partes signatárias expropriem aos acionistas minoritários, o que levaria a um efeito negativo do valor da firma $\left(\mathrm{H}_{1} b\right)$. No entanto, esperamos que a presença de cláusulas de vínculo indiscriminado e universal (genérico) modere negativamente o efeito dos AAs no valor da firma e que a presença de cláusulas de vínculo específico a matérias extraordinárias objeto do acordo modere positivamente o efeito dos AAs no valor da firma. Tais afirmações podem ser visualizadas na Figura 1.

Figura 1. Esquema analítico da relação entre acordos de acionistas e valor da firma

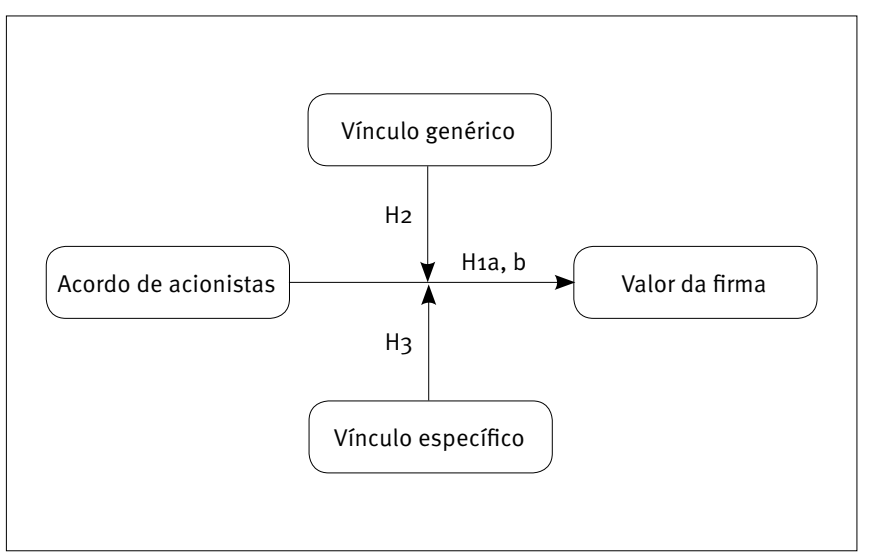

\section{DADOS, VARIÁVEIS E METODOLOGIA}

Com a finalidade de analisar o efeito da vinculação dos votos dos conselheiros aos AAs no valor das empresas listadas nos segmentos especiais da BM\&FBovespa (Novo Mercado, Nível 2 e Nível 1), utilizamos dados das 181 empresas listadas nesses segmentos especiais no ano de 2012. As informações sobre as cláusulas dos AAs foram obtidas diretamente da análise desses acordos, acessados por meio do site da Comissão de Valores Mobiliários (CVM) onde estão arquivados.

Os dados contábeis e de mercado dessas mesmas empresas foram coletados na base de dados Economatica, entre os anos de 2008 e 2012, período para o qual identificamos a vigência desses acordos. A partir da integração desses dados - cláusulas de AAs e dados contábeis e de mercado - e devido à ausência de informações na base Economatica, reduzimos nossa amostra a um painel não balanceado de 644 observações, geradas por 149 empresas, sendo 105 empresas no Novo Mercado, 15 no Nível 2 e 29 no Nível 1.

Nossa amostra difere significativamente do estudo de Carvalhal-da-Silva (2012), uma vez que, naquele estudo, observa-se também o comportamento das empresas do segmento tradicional de governança, onde práticas baseadas em padrões internacionais de governança não são requeridas. Neste estudo, consideramos somente as empresas dos segmentos especiais, aquelas que optaram por práticas mais estritas de governança corporativa, por exemplo, a emissão exclusiva de ações com direito a voto, ou práticas que favoreçam a dispersão de propriedade e controle, independência dos conselheiros e divulgação de informações - ortogonais aos objetivos dos AAs.

\section{Variável dependente}

Para o mercado acionário, é comum o uso da variável Q de Tobin como proxy para o valor da empresa. Essa variável toma como base a soma do valor de mercado da empresa e de sua dívida de curto e longo prazos em relação ao valor contábil dos ativos (Chung \& Pruitt, 1994). Entretanto, essa medida é utilizada para estudos de empresas não financeiras nas quais se pode comparar essas medidas (Lee \& Tompkins, 1999; Lewellen \& Badrinath, 1997). Considerando que nossa amostra é composta tanto por empresas financeiras como não financeiras, optou-se como medida de valor da empresa a razão market-to-book $(P / B)$, que mede a razão entre valor de mercado da empresa e seu valor patrimonial (Fama \& French, 1992).

\section{Variáveis independentes}

Para medir o efeito dos acordos de acionistas e cláusulas "genéricas" e "específicas" de voto do conselho, separamos as 
empresas dos segmentos diferenciados de governança (Novo Mercado, Nível 2 e Nível 1) entre aquelas que possuem ou não AAs por meio da variável "AA" (variável binária que toma valor 1 caso a empresa tenha AA e zero, caso contrário). Em seguida, diferenciamos os AAs entre aqueles com ou sem cláusulas vinculantes do voto dos conselheiros aos interesses dos signatários por meio da variável "Vínculo" (variável binária que toma valor 1 se a empresa possui AA com cláusulas vinculantes de voto do conselho e zero, caso contrário). Por fim, diferenciamos as cláusulas entre "genéricas" e "específicas," por meio da variável "Vínculo específico" (variável binária que toma valor 1 no caso de a empresa possuir AA com cláusulas de vínculo de voto a matérias específicas e zero se possuir cláusulas de vínculo genérico).

\section{Variáveis de controle}

Estrutura de propriedade. Considerando que os AAs tomam, principalmente, a forma de acordos de voto e controle, é fundamental controlar pelo percentual de propriedade (percentual de direitos de fluxo de caixa) e controle (percentual de direitos de voto) dos cinco maiores acionistas da companhia. Para isso, criaram-se as variáveis "Vot 1" (percentual de ações com direito a voto do maior acionista), "Tot 1" (percentual de total de ações do maior acionista), "Vot 4" (percentual de ações com direito a voto em poder do segundo, terceiro, quarto e quinto maiores acionistas), “Tot 4" (percentual de total de ações em poder do segundo, terceiro, quarto e quinto maiores acionistas).

Qualidade da governança corporativa. Considerando que os segmentos especiais de listagem da BM\&FBovespa - Novo Mercado, Nível 2 e Nível 1 - foram criados com o objetivo de aumentar a qualidade da governança corporativa por meio de práticas de governança mais estritas que os requerimentos legais da LSA, e que o segmento "Novo Mercado" é o mais estrito entre os três, tomamos "NM" como proxy para qualidade da governança das empresas. Uma variável binária que toma valor 1 no caso de a empresa estar listada no Novo Mercado, e zero se estiver listada nos níveis 1 ou 2.

Alavancagem financeira. Medimos a alavancagem financeira, variável "Leverage", por meio da razão entre o valor contábil da dívida financeira total e o total de ativos. Tanto a alavancagem financeira da empresa como as demais variáveis contábeis foram incorporadas no modelo de estimação, pelo fato de estarem diretamente associadas ao valor de mercado das empresas, como se observa em outros trabalhos empíricos em governança corporativa e valor da firma (Carvalhal-da-Silva, 2012; Leal \& Carvalhal-da-Silva, 2007; Silveira, Barros, \& Famá, 2006).
Rentabilidade da empresa. A variável "ROA" mede o retorno sobre os ativos por meio da razão entre o EBITDA e o total de ativos.

Tamanho da empresa: Medimos o tamanho da empresa pelo logaritmo natural do valor contábil do total de ativos (Size).

Risco da empresa: Medimos o risco por meio do desvio padrão da razão entre os preços de fechamento da data $(t)$ e data (t-1) em base anual (Risk).

Setor: Considerando que existem diferenças entre as variáveis observadas em relação aos diversos setores industriais, controlamos também pelo efeito setor por meio de (n-1) variáveis binárias para os $\mathrm{n}$ diferentes setores da amostra, considerando a "Indústria manufatureira" como setor de referência.

Identidade do maior acionista: Considerando a importância dos diferentes tipos de acionistas controladores no Brasil (Aguilera et al, 2012), controlamos pelo efeito acionista por meio de variáveis binárias onde empresas cujo maior acionista são "Famílias” foram consideradas categoria de referência.

Tipo de AA: No Brasil, os AAs são, fundamentalmente, motivados para estabelecer: (i) preferência e bloqueio para aquisição de ações, (ii) exercício do direito a voto e (iii) poder de controle. Assim, controlamos o efeito "tipo de acordo" por meio de variáveis categóricas, considerando categoria de referência os "acordos de controle."

\section{Análise descritiva}

A Tabela 1, Painel A, mostra as estatísticas descritivas das variáveis utilizadas comparando as médias entre empresas que possuem ou não AA e, entre as que possuem, aquelas com e sem vínculo do voto dos conselheiros aos AAs.

Em geral, as variáveis utilizadas neste estudo apresentam diferenças significativas entre os diversos grupos de empresas. Observamos que a média de valor de mercado é significativamente diferente entre as empresas com $(1,98)$ e sem vínculo de voto $(2,22)$, mas não estatisticamente significante para as empresas com $(2,05)$ e sem $(2,15)$ AAs.

Conforme estudos anteriores sobre a estrutura de propriedade em empresas brasileiras (Aldrighi \& Mazzer-Neto, 2007; Aldrighi \& Postali, 2010; Leal \& Carvalhal-da-Silva, 2007), a estrutura de propriedade é altamente concentrada, e os grupos de controle estruturam-se por meio de mecanismos de separação de propriedade e controle. Em geral, o maior acionista possui mais direitos ao voto (Vot1) do que ao fluxo de caixa (Tot1) em ambos os tipos de empresas. Em particular, em empresas com cláusulas vinculantes, a participação dos quatro maiores acionistas (Vot4) é significativamente maior do que em 
empresas sem as referidas cláusulas, enquanto a participação do maior acionista é menor. Em parte, uma das motivações dessas cláusulas pode ser o alinhamento entre os acionistas signatários com menor poder de voto, mas que, em conjunto, representam um maior poder de negociação, com o maior acionista.

Tabela 1. Comparação entre empresas com e sem acordos de acionistas e cláusulas vinculantes

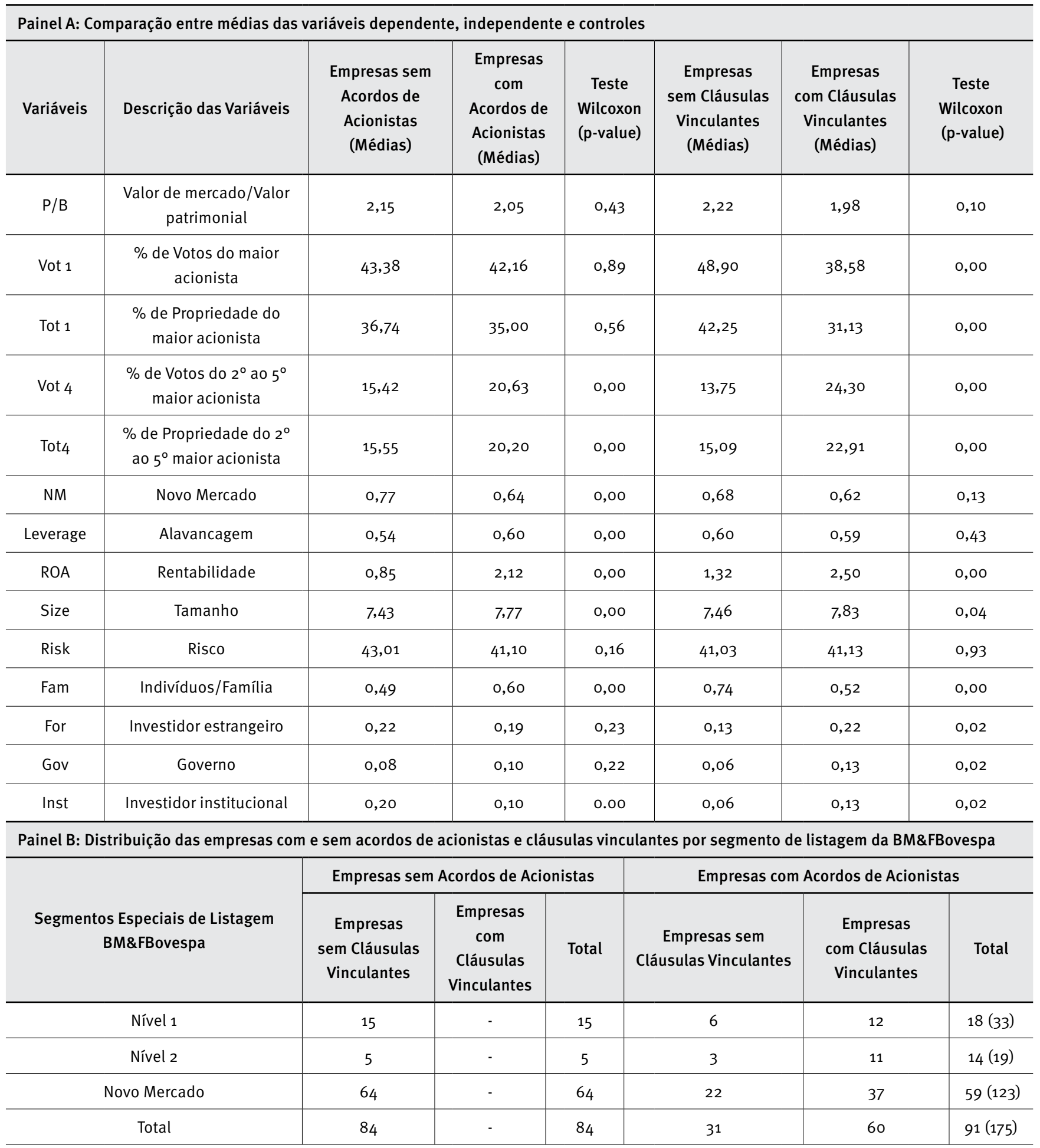

Nota: Os valores de p para o teste de Wilcoxon (rank-sum) de igualdade de médias apresentados são testes não paramétricos e, portanto, não requerem a normalidade das variáveis. 
Em média, as empresas com cláusulas vinculantes são significativamente maiores que aquelas sem cláusulas que vinculem o voto dos conselheiros aos AAs. Além disso, podemos observar que a proporção de empresas sem cláusulas vinculantes no segmento do Novo Mercado é maior que as com cláusulas vinculantes. Em parte, se o argumento de que essas cláusulas verdadeiramente reduzem o poder do conselho pela perda de sua independência, e que o conselho é parte importante da governança corporativa da empresa, espera-se que empresas em níveis mais altos de governança, como o Novo Mercado, façam menor uso dessas cláusulas.

Em relação ao tipo de acionistas majoritários, observa-se que, quando indivíduos e famílias, e investidores estrangeiros, estão entre os acionistas signatários dos AAs, parece não haver diferença entre aquelas empresas que se utilizam ou não das cláusulas vinculantes. Interessante notar que, nas empresas onde o governo está entre os acionistas signatários, as cláusulas que vinculam os votos dos conselheiros são mais comuns (13\% versus 6\%).

No Painel B da Tabela 1, apresentamos a distribuição das empresas por segmento de listagem. Nota-se que $52 \%(64 / 123)$ das empresas do NM não possuem acordos de acionistas, e, das que o fazem, $63 \%$ incluem cláusulas vinculantes de voto do conselho.

A Tabela 2 apresenta a matriz de correlações entre as variáveis. Alinhado com os resultados apresentados na Tabela 1, existe uma correlação negativa entre a presença de cláusulas vinculantes (e cláusulas vinculantes específicas) e a proporção de participação de voto e propriedade do maior acionista, e uma correlação positiva entre essas cláusulas e a estrutura de propriedade dos quatro maiores acionistas. Em parte, isso denota um possível interesse dos acionistas não controladores em balancear o poder de voto com o maior acionista por meio de cláusulas vinculantes, antes que as questões estratégicas da firma se discutam no conselho. Mais importante, a presença de cláusulas vinculantes está negativamente relacionada com o valor da firma (P/B). Com o intuito de medir a colinearidade entre as variáveis independentes e de controle, calculamos os fatores de inflação de variância (VIF) para as variáveis utilizadas, sendo o valor médio 2,24 .

Tabela 2. Correlações entre as variáveis

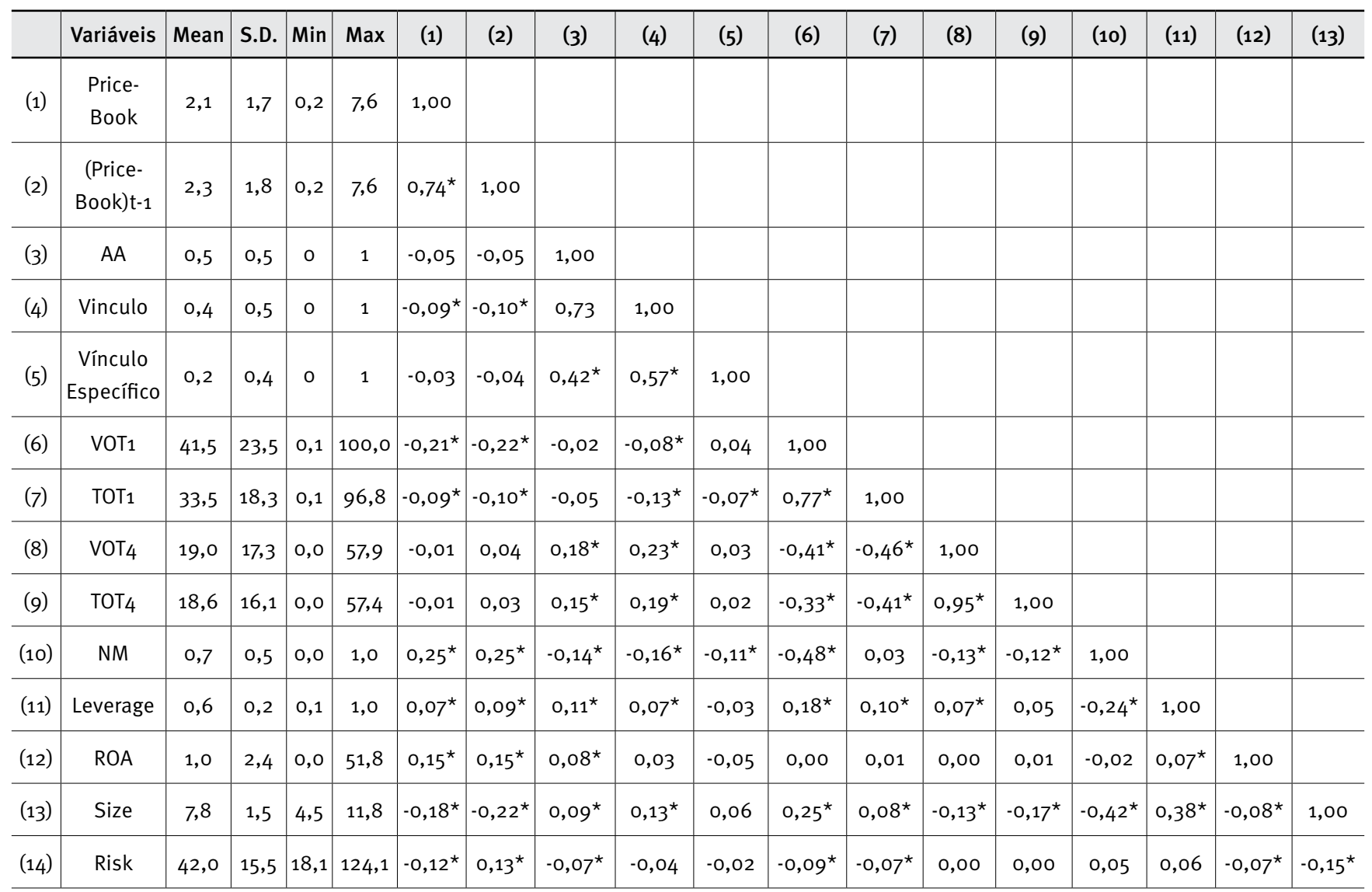

Nota: Fatores de inflação de variância (VIF), excluindo VOT4 e TOT4 utilizados somente como instrumentos, 2.29. * reporta o teste de significância estatística das correlações parciais com p-value <0.10. 


\section{ESPECIFICAÇÃO DO MODELO ECONOMÉTRICO}

Definimos nossa variável de valor da firma pela razão entre o valor de mercado e o valor patrimonial (price-to-book ratio, $P / B$ ) ao longo dos anos, por:

$P / B_{i, t}=\alpha_{o}+\alpha_{1} A A_{i, t}+\alpha_{2}$ Vinculo $_{i, t}+\alpha_{3}$ Vinculo Específico $_{i, t}+\alpha_{4} X_{i, t}+\varepsilon_{i, t}(1)$

Onde AA mede a presença de acordos de acionistas, Vínculo identifica a presença de cláusulas que vinculem os votos dos conselheiros aos interesses dos acionistas signatários do acordo, Vínculo Específico, caso as cláusulas de vínculo estejam associadas a matérias extraordinárias explicitamente definidas no acordo $X_{i, t}$, representa o vetor de características da firma, e $\varepsilon_{i, t}$ representa o erro.

Note-se que, pelo fato de as variáveis Vínculo e Vínculo Específico existirem somente no caso de haver um acordo de acionistas, elas afetam a "força" da relação entre os AAs e o valor da firma, sendo, portanto, variáveis moderadoras dessa relação (Baron \& Kenny, 1986).

Para estimar a Equação (1), primeiramente, examinamos o efeito dos AAs e cláusulas vinculante no valor da firma por meio de um modelo de regressão agrupada ao longo do período entre 2008 e 2012 . Wooldridge (2003) propõe que a escolha do modelo depende do ajuste dos modelos aos seus pressupostos. 0 modelo de regressão agrupada assume que a variância do intercepto é igual a zero para as unidades de corte transversal. Por meio do teste do Multiplicador de Lagrange Modificado (Breusch-Pagan), rejeitamos a hipótese de variância nula.

Em seguida, para controlar uma possível correlação entre Vínculo i,t e o erro oriunda de variáveis não observadas da firma e que, por consequência, possam afetar a estimação dos parâmetros $\alpha_{1}$ e $\alpha_{2}$, introduzimos efeitos fixos da firma. Por meio do teste de Hausman, testamos se a diferença entre os coeficientes de efeitos fixos e aleatórios não é sistemática, rejeitando a hipótese nula (chi-quadrado 43,72, pro.01). Deu-se, portanto, preferência pelo modelo de efeitos fixos em relação ao modelo de efeitos aleatórios.

Conforme comenta Carvalhal-da-Silva (2012), a variável AA captura diferenças sistemáticas entre firmas, já que, por sua natureza endógena, distingue empresas com características de governança onde o potencial de divergência entre majoritários e minoritários se acentua. Assim, como forma de tratar esse potencial problema de endogeneidade, estimamos um modelo de variáveis instrumentais. Para isso, consideramos como instrumentos as variáveis Vot4 e Tot4. Segundo Wooldridge (2003), um instrumento válido deve estar correlacionado com a variável endógena, neste caso AA, e, ao mesmo tempo, não estar correlacionado com a variável dependente,
P/B. Observamos, na Tabela 2, que tanto Vot4 como Tot4 possuem essas características.

Por fim, e considerando a correlação temporal entre o valor de mercado das empresas, estimamos um modelo dinâmico, GMM-Sys, que, à medida que corrige o efeito dinâmico da variável dependente, permite, ao mesmo tempo, controlar a endogeneidade dos AAs por meio de variáveis defasadas como instrumentos.

\section{RESULTADOS}

A Tabela 3 apresenta os resultados das estimações. No Modelo1, o coeficiente da variável que mede a presença de AAs é negativo e significativo a $0,1 \%$. Esse resultado, ao contrário do reportado por Carvalhal-da-Silva (2012), demonstra que firmas com AAs apresentam menor valor de mercado que firmas sem o mesmo instrumento de governança, suportando a Hipótese $1 \mathrm{~b}$. Esse resultado mantém-se para a maioria dos modelos estimados.

Neste estudo, incluímos as variáveis Vínculo e Vínculo Específico - que medem a presença de cláusulas que vinculam o voto dos conselheiros aos interesses dos acionistas signatários do AA. No Modelo 2, o coeficiente do AA segue negativo, enquanto a variável Vínculo apresenta um coeficiente negativo e a variável Vínculo Específico apresenta um coeficiente positivo, ambos significativos a $1 \%$. Por um lado, a presença de cláusulas de vínculo genérico modera negativamente o efeito dos AAs no valor da firma, tornando-o mais negativo, suportando o efeito "entrincheiramento" postulado pela Hipótese 2. Por outro lado, a presença de cláusulas de vínculo específico apresenta um valor menos negativo que as cláusulas vinculantes genéricas, conforme proposto pela Hipótese 3. Esses resultados mantêm-se para os diversos modelos de estimação, sobretudo quando controlamos pela endogeneidade da decisão do AA, Modelos 6 e 8. Em outras palavras, o "efeito entrincheiramento" parece predominar sobre 0 “efeito incentivo," na presença de cláusulas genéricas, enquanto esse resultado tende a inverter-se na presença de cláusulas específicas a matérias extraordinárias no $A A$.

Seguindo a literatura do efeito da adoção a níveis diferenciados de governança no valor da firma (Braga-Alves \& Shastri, 2011; Carvalho, 2003), encontramos um efeito positivo e significativo da variável Novo Mercado (NM) no valor da firma medido pela razão $\mathrm{P} / \mathrm{B}$. Por outro lado, o resultado da estrutura de propriedade (direito de voto, Vot1, e fluxo de caixa, Tot1) é controverso, variando marginalmente entre valores positivos e negativos, sem significância estatística, resultado consistente na literatura de governança (Demsetz \& Lehn, 1985; Demsetz \& Villalonga, 2001), que postula que a estrutura de propriedade é determinada pela preferência dos acionis- 
tas em maximizar seus interesses - endogenamente determinada pelo valor da firma - não devendo, portanto, ter efeito significativo sobre o valor da companhia. De fato, Aguilera et al. (2012) concluem que, apesar dos esforços regulatórios brasileiros e, em particular, da criação do Novo Mercado, em aumentar a eficiência e desenvolver o mercado de capitais visando a uma maior participação de acionistas minoritários e, assim, promover reduções significativas nos níveis de concentração de propriedade, o fato é que as empresas listadas na
BMF\&Bovespa continuam a ser altamente concentradas nas mãos de um pequeno número de proprietários. Nesse cenário, onde o acionista majoritário, ou um bloco de controle, por meio de acordos de acionistas, detém o controle das decisões empresariais, as práticas de governança passam a ter um papel fundamental para assegurar os direitos dos minoritários, sobretudo onde as instituições legais não são fortes o suficiente para garantir os direitos contratuais (Claessens \& Yurtoglu, 2013).

\section{Tabela 3. Efeitos das cláusulas vinculantes no valor da firma}

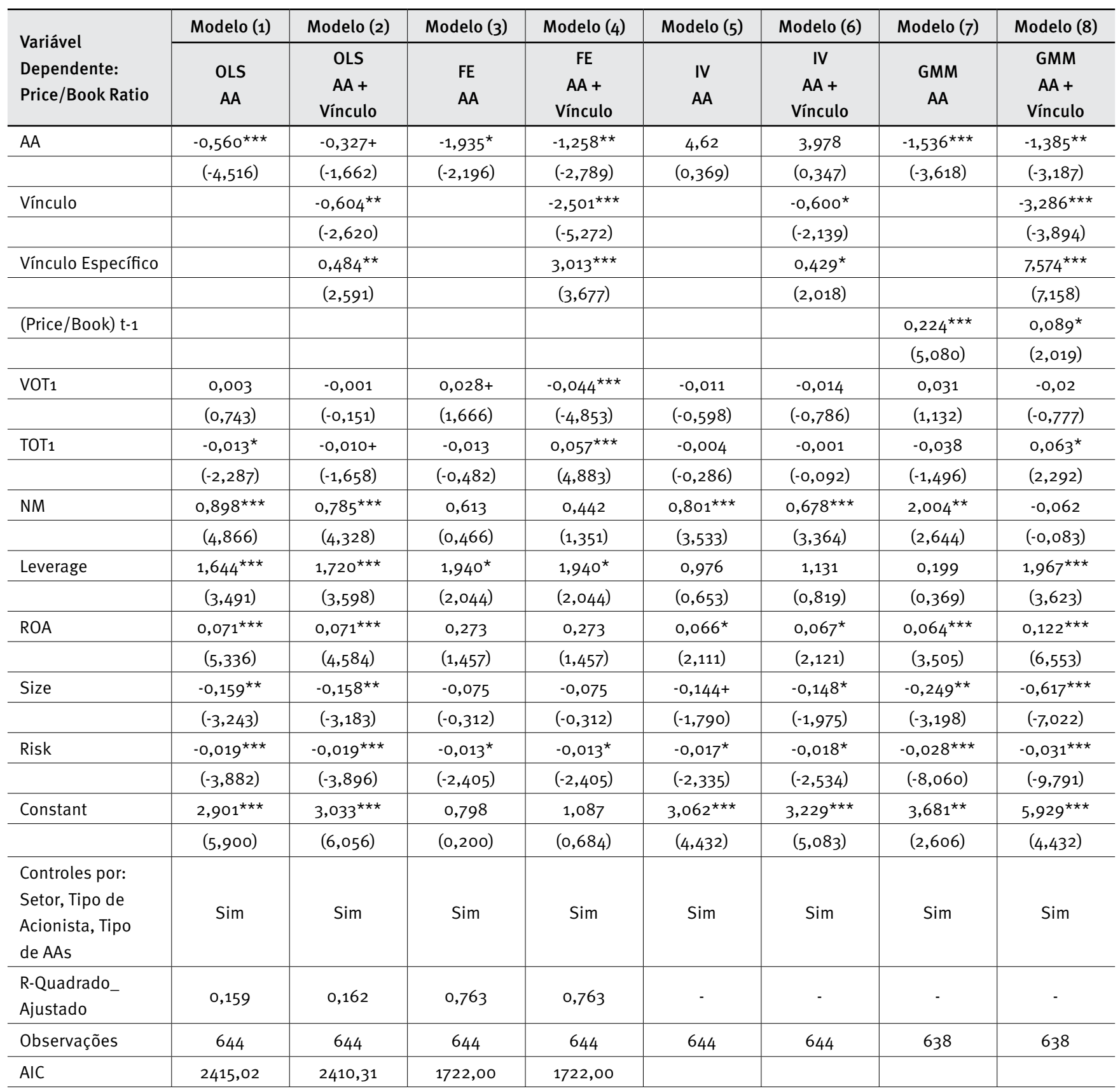

Nota: Onde: +, *, **, *** representam o nível de significância estatística a 10\%, 5\%, 1\%, e o,1\% respectivamente. 
Entre as demais variáveis de controle, a rentabilidade da empresa e a alavancagem financeira apresentam um efeito positivo e significativo no valor da empresa. Se, por um lado, é esperado que uma empresa com melhor desempenho operacional tenda a ter um maior valor, o efeito positivo da dívida poderia ser considerado contraditório. Entretanto, pode-se argumentar que tal efeito mede a capacidade de financiamento externo da empresa, uma vez que se controla também pelo risco. Mais ainda, considerando que a dívida pode funcionar como um fator redutor de problemas de agência (Jensen \& Meckling, 1976), já que limita a discricionariedade dos administradores, o mercado precifica positivamente o nível de endividamento. Finalmente, o risco também tem efeito significativo, sendo percebido negativamente pelo mercado.

De maneira geral, os resultados apontam que o efeito da presença dos AAs no valor de firma pode ser alterado em função das características de cada AA, em particular, das cláusulas que vinculam o voto dos conselheiros aos interesses dos acionistas signatários. Nesse caso, as cláusulas de vínculo indiscriminado e universal, vínculo genérico, moderam negativamente o efeito dos AAs - "efeito entrincheiramento" $\left(\mathrm{H}_{2}\right)$, enquanto cláusulas específicas a temas extraordinários e relevantes ao acordo moderam positivamente o efeito dos acordos no valor da empresa, e, nesse, caso, os resultados apontam para a prevalência do "efeito incentivos" $\left(\mathrm{H}_{3}\right)$.

\section{DISCUSSÃO E CONCLUSÃO}

A literatura no Brasil sobre os efeitos dos AAs nos resultados das empresas e, finalmente, no seu valor de mercado é incipiente. Uma exceção se faz ao trabalho de Carvalhal-da-Silva (2012), que analisa o efeito da existência de AA no valor das empresas listadas na BM\&FBovespa e, mais que isso, desenvolve um índice para medir a qualidade desses acordos, concluindo que os AAs aumentam a proteção aos acionistas minoritários e, em consequência, são benéficos ao valor da firma.

No entanto, o estudo de Carvalhal-da-Silva (2012) parece estar baseado numa série de premissas otimistas quanto à proteção assegurada aos minoritários por meio desses acordos, negligenciando o fato de que a maioria dos acionistas minoritários da empresa não participará desse acordo e, ao contrário, estará sujeita à expropriação de benefícios privados do controle pelo grupo controlador constituído pelo AA.

Assim, nosso trabalho busca analisar pormenorizadamente a existência de cláusulas de vinculação dos votos dos membros do conselho de administração aos interesses dos acionistas signatários do AA. Além da análise qualitativa, estimamos um modelo para identificar o efeito dessas cláusulas no valor da firma. Os resultados demonstram que o efeito positivo identificado na literatura (Carvalhal-da-Silva, 2012) não se observa numa amostra restrita aos segmentos especiais de listagem da BM\&FBovespa. Ao contrário, para essas empresas, o efeito dos AAs é negativo mesmo controlando pela endogeneidade dessa decisão e o efeito dinâmico do valor das empresas.

Além disso, identificamos que esse efeito é moderado não somente pela presença das cláusulas que vinculam o voto dos conselheiros, mas também pelas características de tais cláusulas. Assim, o debate sobre os efeitos dos AAs precisa considerar a realidade dos acordos e sua prática, a redação de suas cláusulas, para alcançar conclusões adequadas ao contexto em que tais instrumentos se inserem.

Corroborando o estudo de Gorga e Gelman (2012), os AAs parecem operar em parte - cláusulas genéricas - como um instrumento de anulação do dever de independência e comprometimento do pleno exercício das funções do conselho. Nesse contexto, o interesse do controlador representado no AA não pode ser presumido como de acordo com o interesse social da companhia, representado pelo seu valor de mercado.

Se, por um lado, o AA pode ter um efeito positivo no valor da firma por meio do "efeito incentivo," onde os acionistas de controle passam a ter interesse direto no desempenho da empresa, uma vez que possuem a maior parte de seus recursos investidos na empresa, por outro, esses mesmos acionistas de controle podem extrair benefícios privados em detrimento dos acionistas minoritários, ocorrendo o "efeito entrincheiramento." Assim, a partir de nossos resultados, pode-se concluir que o predomínio de um ou outro efeito no valor da empresa se dá por meio das características intrínsecas do acordo, quais sejam suas cláusulas vinculantes.

Assim, uma importante implicação do ponto de vista regulatório é certificar-se de que essas cláusulas estejam orientadas ao interesse social da firma e, não necessariamente, aos interesses de uma minoria - acionistas signatários. Em outras palavras, ao permitir aos acionistas signatários a faculdade na adoção de cláusulas vinculantes, o regulador brasileiro não protege, ex-ante, os interesses dos minoritários. Em particular, cláusulas que vinculem os votos dos administradores de maneira indiscriminada (vinculo genérico) são, do ponto de vista econômico, prejudiciais ao valor da companhia, e, do ponto de vista jurídico, inválidas e ineficazes (Carvalhosa, 2011; Gorga \& Gelman, 2012). 


\section{LIMITAÇÕES E RECOMENDAÇÃO DE ESTUDOS FUTUROS}

A amostra que utilizamos concentra-se em empresas dos segmentos especiais de listagem da BM\&FBovespa. Se, por um lado, isso permite identificar diferenças num grupo específico de empresas onde os níveis de governança são mais estritos, por outro, reduz a abrangência da amostra e a variância das variáveis observadas. Em parte, isso explica algumas diferenças em relação a estudos anteriores (Carvalhal-da-Silva, 2012), sobretudo no que se refere aos modelos de estimação dos AAs (sem as cláusulas vinculantes, Modelos 1, 3, 5, e 7 da Tabela 3). Além disso, é pequena a abrangência temporal da amostra, que inclui um painel de cinco anos. Assim, estudos futuros podem ampliar a amostra, sem perder a generalidade das análises. Em particular, uma análise de eventos sobre a lei que reformou a LSA em 2001 pode dar maior clareza ao efeito da mudança regulatória na governança das empresas no mercado de capitais brasileiro.

Seria interessante, também, analisar a utilização de AAs em outros países como forma de identificar o impacto e a natureza das diferenças institucionais nesses mecanismos de governança. Por fim, considerando o conjunto de mecanismos internos e externos de governança, outros estudos podem identificar os efeitos de substituição e complementariedade entre os AAs e outros mecanismos internos.

\section{REFERÊNCIAS}

Adamek, M. V. (2009). Responsabilidade civil dos administradores de S/A (e as ações correlatas). São Paulo: Saraiva.

Aguilera, R., Kabbach, L. R., Lee, J., \& You, J. (2012). Corporate governance in emerging markets. In G. Morgan \& R. Whitley (Eds.). Capitalisms and capitalism in the twenty-first century (pp. 319-344). Oxford: Oxford University Press.

Aldrighi, D., \& Mazzer-Neto, R. (2007). Evidências sobre as estruturas de propriedade de capital e de voto das empresas de capital aberto no Brasil. RBE-Revista Brasileira de Economia, 61(2), 129-152.

Aldrighi, D. \& Postali, F. A. S. (2010). Business groups in Brazil. In A. Colpan, T. Hikino \& J. Lincoln (Eds.). The Oxford handbook of business groups (pp. 353-386). Oxford: Oxford University Press.

Aragão, P. C. (2002). A disciplina do acordo de acionistas. In J. Lobo (Ed.). Reforma da lei das sociedades anônimas: inovações e questões controversas da Lei $n=10.303$, de 31.10.2001. Rio de Janeiro: Forense.

Baglioni, A. (2010). Shareholders' agreements and voting power: evidence from Italian listed firms. Applied Economics, 43(27), 4043-4052.

Baron, R. \& Kenny, D. (1986). The moderator-mediator variable distinction in social psychological research: conceptual, strategic, and statistical considerations. Journal of Personality and Social Psychology, 51(6), $1173-1182$
Berglöf, E. \& Perotti, E. (1994). The governance structure of the Japanese financial keiretsu. Journal of Financial Economics, 36(2), 259-284.

Berle, A. A, \& Means, G. C. (1932). The modern corporation and private property. New York: Commerce Clearing House.

Bocater, M. I. \& Camargo, J. L. (2001). Conselheiros laranja. O Globo, 7. Recuperado em 20 maio, 2012, de http://www.econ.puc-rio.br/gfranco/CamargoBocater.htm

Braga-Alves, M. \& Shastri, K. (2011). Corporate governance, valuation, and performance: evidence from a voluntary market reform in Brazil. Financial Management, 40(1), 139-157.

Burkart, M., Gromb, D., \& Panunzi, F. (1997). Large shareholders, monitoring, and the value of the firm. Quarterly Journal of Economics, 112(3), 693-728.

Capresse, J. N., Clerc, C., \& Becht, M. (2007). The report on the proportionality principle in the European Union. Brussels: European Commission.

Carvalhal-da-Silva, A. (2012). Do shareholder agreements affect market valuation?: Evidence from Brazilian listed firms. Journal of Corporate Finance, 18(4), 919-933.

Carvalho, A. G. (2003). Efeitos da migração para os níveis de governança da Bovespa. Recuperado em 4 março, 2003, de http:// www.novomercadobovespa.com.br

Carvalhosa, M. (2011). A vinculação dos administradores ao Acordo de Controle ( $\S \S 8^{\circ}$ e $9^{\circ}$ do artigo 118 da LSA). In A. Wald, F. Gonçalves \& M. A. S. de Castro. Sociedades anônimas e mercado de capitais (pp. 41-46). São Paulo: Quartier Latin.

Carvalhosa, M. A. (2009). Comentários à lei das sociedades anônimas (Vol. 3, 4a ed.). São Paulo: Saraiva.

Cerezetti, S. C. N. (2010). Administradores independentes e independência dos administradores (regras societárias fundamentais ao estímulo do mercado de capitais brasileiro). In L. A. N. M. Azevedo. Poder de controle e outros temas de direito societário e mercado de capitais (pp. 575-593). São Paulo: Quartier Latin.

Chemla, G., Habib, M., \& Ljungqvist, A. (2007). An analysis of shareholder agreements. Journal of European Economic Association, 5(1), 93-121.

Chung, K. H. \& Pruitt, S. W. (1994). A simple approximation of Tobin's Q. Financial Management, 23(3), 70-74.

Claessens, S. (2006). Corporate governance and development. World Bank Research Observer, 21(1), 91-122.

Claessens, S., Djankov, S., Fan, J., \& Lang, L. (2002). Disentangling the incentive and entrenchment effects of large shareholdings. Journal of Finance, 57(6), 2741-2771.

Claessens, S., Djankov, S., \& Lang, L. (2000). The separation of ownership and control in East Asian Corporations. Journal of Financial Economics, 58(1-2), 81-112.

Claessens, S. \& Yurtoglu Y. B. (2013). Corporate governance in emerging markets: a survey. Emerging Markets Review, 15(2013), 1-33.

Coffee, J. C. (2001). The rise of dispersed ownership: the roles of law and state in the separation of ownership and control. Yale Law Review, 111(1), 1-82.

Demsetz, H. \& Lehn, K. (1985). The structure of corporate ownership: causes and consequences. Journal of Political Economy, 93(6), 11551177 .

Demsetz, H. \& Villalonga, B. (2001). Ownership structure and corporate performance. Journal of Corporate Finance, 7(3), 209-233. 
Djankov, S., La Porta, R., López-de-Silanes, F., \& Shleifer, A. (2008). The law and economics of self-dealing. Journal of Financial Economics, 88(3), 430-465.

Eizirik, N. (2003). Acordo de Acionistas - arquivamento na sede social - vinculação dos administradores de sociedade controlada. Revista de Direito Mercantil, Industrial, Econômico e Financeiro, 37, 45-53.

Eizirik, N. (2011). Lei das SA comentada. São Paulo: Quartier Latin.

Enriques, L. \& Volpin, P. (2007). Corporate governance reforms in continental Europe. Journal of Economic Perspectives, 21(1), 117-140.

Faccio, M. \& Lang, H. P. (2002). The ultimate ownership of Western European corporations. Journal of Financial Economics, 65(3), 365-395.

Fama, E. \& French, K. (1992). The cross-section of expected stock returns. Journal of Finance, 47(2), 427-465.

Franco, G. (2001). A nova Lei das S.A. e o Conselheiro Laranja. O Estado de S. Paulo, 15. Recuperado em 20 maio, 2012, de http://www.econ. puc-rio.br/gfranco/a125.htm

Franks, J. \& Mayer, C. (2001). Ownership and control of German corporations. The Review of Financial Studies, 14(4), 943-977.

Gomes, A. \& Novaes, W. (2006). Sharing o control versus monitoring as corporate governance mechanisms [Working Paper]. University of Washington. Recuperado em 22 agosto, 2014, de http://apps.olin.wustl. edu/faculty/gomes/gomesnovaes.pdf

Gorga, E. \& Gelman, M. (2012). O esvaziamento crescente do Conselho de Administração como efeito da vinculação de seu voto a acordos de acionistas no Brasil, [Working Paper]. Recuperado em 31 março, 2013, de http://www.ibgc.org.br/Download.aspx?Ref=Arquivos\&CodArqui$v o=1121, p p .1-21$.

Grossman, S. \& Hart, O. (1980). Takeover bids, the free-rider problem, and the theory of the corporation. The Bell Journal of Economics, 11(1), 42-64.

Hart, O. (1995). Corporate governance: some theory and implications. The Economic Journal, 105(430), 678-689.

Jensen, M. C. \& Meckling, W. (1976). Theory of the firm: managerial behavior, agency costs and ownership structure. Journal of Financial Economics, 3(4), 305-360.

Johnson, S., La Porta, R., Lopez-de-Silanes, F., \& Shleifer. A. (2000). Tunneling. American Economic Review, 90(2), 22-27.

La Porta, R., López-de-Silanes, F., \& Shleifer, A. (1999). Corporate ownership around the world. Journal of Finance, 54(2), 471-517.

Leal, R. P. C. \& Carvalhal-da-Silva, A. L. (2007). Corporate governance and value in Brazil (and in Chile). In A. Chong \& F. López-de-Silanes (Eds.). Investor protection and corporate governance: firm-level evidence across Latin America. Washington, DC: World Bank. pp. 213-288.
Lee, D. E. \& Tompkins, J. G. (1999). A modified version of the Lewellen and Badrinath of Tobin's Q. Financial Management, 28(1), 20-31.

Lei n. 6.404, de 15 de dezembro de 1976 (1976). Recuperado em 31 março, 2013, de http://www.planalto.gov.br/ccivil_03/leis/16404compilada.htm

Lewellen, W. G. \& Badrinath, S. G. (1997). On the measurement of Tobin's Q. Journal of Financial Economic, 44(1), 77-122.

Morck, R., Wolfenzon, D., \& Yeung, B. (2005). Corporate governance, economic entrenchment, and growth. The Journal of Economic Literature, 43(3), 655-720.

Pedreira, J. L. B. (2002). Acordo de acionistas sobre controle de grupos de sociedades. Validade da estipulação de que os membros do conseIho de administração de controladas devem votar em bloco segundo orientação definida pelo grupo controlador. Revista de Direito Bancário, do Mercado de Capitais e da Arbitragem, 5(15), 226-248.

Salomão, C. Filho. (2006). 0 novo direito societário (3a ed.). São Paulo: Editora Malheiros.

Shleifer, A. \& Vishny, R. (1986). Large shareholders and corporate control. Journal of Political Economy, 94(3), 461-488.

Silveira, A. M., Barros., L. A. B. C., \& Famá, R. (2006). Atributos corporativos, qualidade da governança corporativa e valor das companhias abertas no Brasil. RBFin-Revista Brasileira de Finanças, 4(1), 1-30.

Toledo, P. F. C. S. (2002). Modificações introduzidas na Lei das Sociedades por Ações, quanto à disciplina da administração das companhias. In J. Lobo (Ed.). Reforma da Lei das Sociedades Anônimas (2a ed, pp. 423-452). Rio de Janeiro: Forense.

Wald, A. (2001). A evolução do regime legal do conselho de administração, os acordos de acionistas e os impedimentos dos conselheiros decorrentes de conflitos de interesse. RDB-Revista de Direito Bancário e do Mercado de Capitais, 4(11), 13-30.

Wald, A. (2002a). A reforma da lei das sociedades anônimas: os direitos dos minoritários na nova lei das S.A. (pp. 219-247) In J. Lobo (Ed.) Reforma da Lei das Sociedades Anônimas. Rio de Janeiro: Editora Forense.

Wald, A. (2002b). 0 governo das empresas. Revista de Direito Bancário, do Mercado de Capitais e da Arbitragem, 15(5), 53-78.

Wooldridge, J. M. (2003). Econometric analysis of cross section and panel data. Cambridge, MA: MIT Press.

Wright, T. (1971). Shareholder pooling agreements - validity, legality and enforcement. Arkansas Law Review, 501, 501-525.

Young, M., Peng, M., Ahlstrom, D., Bruton, G., \& Jiang, Y. (2008). Corporate governance in emerging economies: a review of the principal-principal perspective. Journal of Management Studies, 45(1), 196-220. 